\title{
Assessing the Nexus Between Stock Market Performance and Covid-19: Evidence from Global Perspective
}

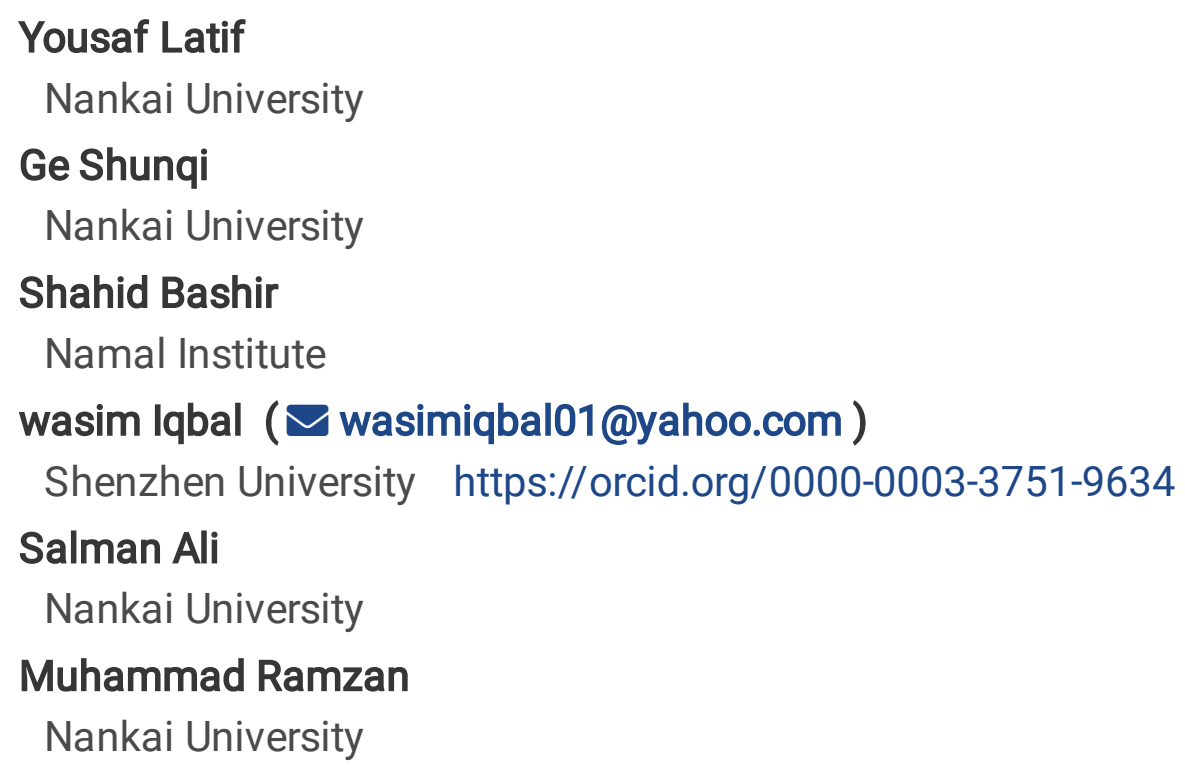

\section{Research Article}

Keywords: Return, COVID-19, Wavelet, Stock volatility

Posted Date: May 17th, 2021

DOl: https://doi.org/10.21203/rs.3.rs-382497/v1

License: (9) (i) This work is licensed under a Creative Commons Attribution 4.0 International License. Read Full License 


\title{
1 Assessing the Nexus Between Stock Market Performance and Covid-19: 2 Evidence from Global Perspective
}

\author{
3 Yousaf Latif ${ }^{1}$, Ge Shunqi ${ }^{1}$, Shahid Bashir ${ }^{2}$, Wasim Iqbal ${ }^{3}$, Salman Ali ${ }^{1}$, Muhammad Ramzan ${ }^{1}$ \\ 1 Institute of International Economics, Nankai University, Tianjin, 300071, PR China. \\ 2 Business Studies Department, Namal Institute Mianwali, Pakistan \\ 3 Department of Management Science, College of Management, Shenzhen University, \\ Shenzhen, China \\ myousaf_latif@hotmail.com; geshunqi@vip.163.com; shahid.bashir@namal.edu.pk; \\ wasimiqbal01@yahoo.com; ranasalmanali1986@gmail.com; ramzanalambwp@gmail.com
}

11 Corresponding Author: Wasim Iqbal (wasimiqbal01@yahoo.com)

\section{Abstract}

This study described an empirical link between COVID-19 fear and stock market volatility. Studying COVID-19 fear with stock market volatility is crucial for planning adequate portfolio diversification in international financial markets. The study used AR (1) - GARCH $(1,1)$ to measure stock market volatility associated with the COVID-19 pandemic. Our findings suggest that COVID-19 fear is the ultimate cause driving public attention and is a stock market volatility. The results demonstrate that stock market performance and GDP growth decreased significantly through average increases during the pandemic. Further, a $1 \%$ increase in COVID-19 cases the stock return and GDP decrease with a $0.8 \%, 0.56 \%$, respectively. However, GDP growth demonstrated a slight movement with stock exchange. Moreover, public attention to the attitude of buying or selling was highly dependent on the COVID-19 pandemic reported cases index, death index, and global fear index. Consequently, investment in the gold market, rather than in the stock market, is recommended. The study also suggests policy implications for key stakeholders.

Keywords: Return; COVID-19; Wavelet; Stock volatility

\section{Introduction}

The global economy was hit hard by the COVID-19 pandemic, which created panic in global financial markets. The aim of this study was two-fold: first, to determine how much of the increase in stock volatility can be traced to COVID-19, and second, to examine the relevant economic factors, such as financial development and economic growth. Drastic and impactful changes have been witnessed since the beginning of 2020, and their impact has led to various events that have 
32 interfered with different aspects of human life, including the social and economic arenas. Due to

33 this impact, several economies are currently trying to recover from recessions. The pandemic hit

34 almost every aspect of the economy hard, including consumption, trade, manufacturing, supply

35 chains, and financial behaviours. Due to COVID-19 uncertainty, massive recovery plans are called

36 for worldwide to counter these adverse effects on economies. Different approaches have been

37 suggested by different sources internationally, but the ideal recovery method is considered to be based on sustainable post-COVID-19 strategies (Yoshino et al., 2020). Therefore, countries should plan for different stages of response to COVID-19, including an emergency stage, an exit strategy,

40 and the new normal life (Rizvi et al., 2020; Mirza et al., 2020a; Yarovaya et al., 2021; Mirza et al.,

41 2020b). Moreover, the policies for all stages must be sustainable.

42 The impact of COVID-19 fear on public attention to stock market volatility has been under-

43 studied. This is one of the first studies to test the effect of COVID-19 fear on stock market

44 volatility. This acts as a pillar in its subject of the development of the economic growth that fulfils

45 a country's commercial and energy needs (Anser et al., 2020b; 2020c). Due to shock and fear,

46 stock prices fell worldwide: According to data released by the British Broadcasting Corporation

47 (BBC) on March 31, 2020, the Dow Jones Industrial Average and FTSE 100 fell by 23\% and 25\%,

48 respectively, the largest quarterly decline since 1987. During the same period, Standard \& Poor's

49500 Index fell by $20 \%$, the most since the 2008 financial crisis. Economists made terrible

50 predictions about the economic recession. According to the 'Global Economic Outlook' (June 51 2020), the pandemic would plunge most of the world's economies into recession, representing the 52 world's highest annual per capita production reduction since 1870 . The report also pointed out that 53 the real global GDP contraction would be 5.2\%. Developed countries would have a growth rate of $547.5 \%$, while emerging and developed markets would have a growth rate of $2.5 \%$. Because 
multinational actors compete, a sudden spike in energy prices would have a detrimental effect on demand and could spark a global economic recession (Anser et al., 2020e) (Anser et al., 2020a).

The significant negative impacts of COVID-19 investment on stock exchange sector growth show that foreign direct investment (FDI) is the main determinant of foreign integration in both developed and developing economies. Most academics have emphasised the effect of FDI on economic growth. The global economy suffered significant losses because of COVID-19. As a result, ways to cope with the pandemic's effect on the global economy have been a popular subject in recent months (Uddin et al., 2021; Engelhardt et al., 2021; Lyócsa \& Molnár, 2020). Furthermore, academic study of the modelling and forecasting of stock market volatility has always been a challenge. This report nevertheless explored its impact on development in the stock exchange market for the first time, providing insights for policymakers. Policymakers should provide international buyers with enticing offers for stock exchange investments. Because FDI increases stock exchange sector efficiency, it also makes a positive contribution to GDP through stock exchange sector production. The stock exchange sector serves household and industry grain and raw material requirements. The positive effect of the entire selling price index on the stock exchange sector's development indicates that local and foreign demand consume the stock exchange industry's supply. Positive results mean that production falls short of demand, contributing to an increase in price costs and the ability of manufacturers to generate more. The rise in demand could be attributed to the growth and wages of the local and global populations.

It increased uncertainty in financial markets, which dragged stock market volatility into a hostile region (W. Zhang et al., 2020), halting market stability (Rizvi et al., 2020; Mirza et al., 2020a). This led to a new argument, linking the fear index of infectious disease and, simultaneously, the coronavirus, with a severe effect on stock market volatility (Alemzero et al., 
2020b; Yarovaya et al., 2021; Mirza et al., 2020b; Alemzero et al., 2020a). Such conditions favour the activities, balance, and growth of business. Studies have also shown that the COVID-19 pandemic supported climate change well (Rowan \& Galanakis, 2020; Daughton, 2020).

The purpose of this study was to test the positive and negative impacts of COVID-19 on stock market volatility. Our contribution also included the assessment of COVID-19 and stock price comments. We used the $\operatorname{AR}(1)-\operatorname{GARCH}(1,1)$ model, which is reliable for estimating the impact of COVID-19 fear on public attention to stock market volatility. This study also aimed to evaluate the plans and measures taken by different developed nations, the reasons for such approaches, and the efficiency of their recovery strategies (W. Zhang et al., 2020). We contributed to this area in several ways. We investigated the relationship between COVID-19 and stock exchanges, such as S\&P500, NASDAQ, DOW, DAX, CRIA, and Cyprus. We highlighted that economic recovery strategies have been called for while the pandemic is ongoing.

The rest of the paper is organised as follows: Section 2 summarises the literature review and background. Section 3 explains the techniques used in this study. Section 4 describes the results and discussion, and Section 5 concludes the study and provides policy implications.

\section{Literature Review and Background}

In January 2020, COVID-19 was brought to the world's attention. The accelerating spread of the virus and the growing number of reported cases prompted the Chinese government to move quickly. On January 23, 2020, the entire city of Wuhan was put under lockdown, shocking the world and later proving to be a highly powerful strategic move by the Chinese government. The WHO called the epidemic in China a global health emergency of international significance a week later (PHEIC). There were 7,711 reported cases at the time, with 83 cases in 18 countries outside China. The crisis began to affect the global economy. For instance, according to International 
101 Monetary Fund statistics, as a world leader in automobile exports, the Japanese economy was 102 likely to shrink by $8 \%$ during the 2020 third quarter and later expected to expand to the new 103 normal. Despite Japan's strategies, the country's economy did not respond as quickly as expected. 104 The overall recovery plan is sub-divided into two phases: economic emergency support. During 105 this period, the government would attempt to stabilise the economy as much as possible until the 106 end of the contagion (N. Iqbal et al., 2020). It is a strategic period immediately following the end 107 of the pandemic, the timing of which is unknown. This is a period when demand will be stimulated 108 to normal levels, and other monetary tools will be in full control. During this period, there will be 109 a focus on the most affected sectors, such as tourism, the leisure industry, and service sectors 110 (restaurants, bars, etc.). Some of the strategies involve direct stipends to all citizens and to selected 111 businesses to cover the minimum daily needs and to compensate a part of their business loss. The 112 stipend also aims to maintain the daily demand for goods at a normal level. This will not only 113 maintain purchasing power but also boost industrial output. Support plans also include the 114 provision of loans at almost $0 \%$ interest. The country identified the core importance of the money 115 supply within the economy and decided to provide risk- and interest-free loans through the Bank 116 of Japan (Ashraf, 2020a), with the aim of encouraging more business people and other stakeholders 117 to expand their business scope and retain the labour force (Phan \& Narayan, 2020).

118 A total amount of JPY 1 billion was set aside to support small-scale businesses. To ensure 119 the continuous flow of goods into Japan, Japanese customs declared import duty relief on all 120 imported goods. This facilitates the availability of goods and provides price relief to consumers, 121 thus boosting demand to a more normal level. This plan was accompanied by a sophisticated 122 subsidy budget for goods that are less in demand during an era of lockdowns. It has been well 123 explained that Japan cannot rely on external demand to recover its economy, but it could try to 
124 reduce the COVID-19 impact through massive export of automobiles, optimal operation of their

125 heavy industries, and further investment in high-tech goods that are still in high demand, despite

126 the pandemic. This will indirectly improve the Japanese economy's progression towards

127 recovery(W. Iqbal et al., 2020). The co-movement of world equity markets is often used as a

128 barometer of economic globalisation and financial integration. Several studies have tested co-

129 movement within international stock markets (Corbet et al., 2020; Zaremba et al., 2020; Straif-

130 Bourgeois \& Robinson, 2020), revealing significant effects on international stock returns,

131 volatility, portfolio diversification, and inter-temporal stability (Iqbal et al., 2019a),(Iqbal et al.,

132 2019b). Studies have also revealed that financial crises significantly affect international stock

133 market performance. Studying the co-movement of the global fear index of the COVID-19 crisis

134 with study topicality is still a missing link. Therefore, this study hypothesised a significant

135 relationship between the COVID-19 fear index and public attention to stock market volatility.

136 The world economy has faced enormous setbacks owing to the intensive lockdowns that

137 numerous countries have enforced to deal with the numerous deaths and infections caused by the

138 continued rapid spread of the coronavirus (Barbier \& Burgess, 2020). The global economy suffered

139 a significant decline during these government-imposed lockdowns and continues to suffer a great

140 deal, because of the closure of various businesses. Many disputed the labour, whereas industries

141 such as tourism, education, and transport completely shut down (Quigley et al., 2020; Chandio et

142 al., 2020). We studied the relevant literature from two viewpoints, focusing on recent publications

143 on the financial and socioeconomic impacts of the COVID-19 pandemic: (1) transmission

144 instability during the COVID-19 crisis and (2) the association of COVID-19 indicators with stock

145 market performance and economic uncertainty. Several new reports have looked at the financial

146 and socioeconomic impacts of COVID-19. For example, during the pandemic, Akhtaruzzaman et 
147 al. (2021) used the DCC method to investigate contagion dissemination for both financial and 148 nonfinancial companies between China and the G7 economies. They discovered that conditional 149 associations between equity returns of both financial and nonfinancial companies increased 150 significantly (Salisu \& Akanni, 2020). They also stated that the extent of the rise in these 151 correlations was far higher for financial companies, indicating they played a major role in financial 152 contagion propagation between China and the G7. Finally, they showed that, in most situations, 153 the ideal hedge ratios increased considerably, implying higher hedging costs during the COVID15419 crisis era. According to Corbet et al. (2020), it is not surprising that the Chinese markets were 155 the epicentre of both the physical and financial contagion at the start of the COVID-19 pandemic. 156 They also demonstrated that the word 'corona' has sharp, complex, and recent similarities. Zhang 157 et al. (2020) argued that COVID-19's accelerated spread has had drastic consequences for stock markets across the globe, culminating in a substantial rise in global financial market instability and 159 significant losses for investors in a brief span of time (Narayan et al., 2020).

\section{Data and methodology}

To measure stock market volatility, global COVID-19 pandemic-related daily volatility index statistics were used. According to WHO (2020), the incubation period of most coronavirus positive cases is approximately 14 days in incubation centres. Endorsing the WHO verdict, this period of 14 days shows the maximum number of days for positive coronavirus cases in incubation centres.

165 For the empirical estimation, the data were analysed in four panels: 16 December 2019 to 16 April 166 2020 (Panel 1), 17 April 2020 to 16 June 2020 (Panel 2), 17 June 2020 to 16 August 2020 (Panel 3), and 17 August 2020 to 16 December 2020 (Panel 4). Using international stock index data, the 168 study's preliminary estimation highlighted the pattern of stock index volatility through figures during the COVID-19 outbreak (Aydın \& Ari, 2020; Akinsomi, 2020). These figures provide a 
170 rich understanding of stock market volatility in co-movement with the global fear index of the

171 COVID-19 outbreak persisting in international stock indexes. Thus, the fear index of the COVID-

17219 outbreak is trending towards fear in international markets and raising public attention to stock

173 exchange issues. To estimate the research models of the recent study, marginal distributions

174 showing AR (1) - GARCH (1,1) were used, and the results for the interconnected distribution

175 estimation were used. The AR (1) - GARCH $(1,1)$ model was previously discussed and 176 operationalised by Glosten, Jagannathan, and Runkle (1993). The AR $(1)$ - GARCH $(1,1)$ model 177 is explained as follows, where:

$$
\begin{gathered}
\sigma_{t}^{2}=\omega+\sum_{i=1}^{q} \alpha_{i} \varepsilon_{t-1}^{2}+\sum_{j=1}^{p} \beta_{j} \sigma_{t-j}^{2} \\
V_{i, t}=\beta_{0}+\beta_{1} V_{i, t}+\beta_{2}\left(V_{i, t-1}\right)+\beta_{3} \sigma+\varepsilon_{i, t}
\end{gathered}
$$

$\sigma_{t}^{2}$ shows the conditional variance, $\varepsilon$ shows the residual error, The model holds eights constructs 181 showing the parameters of estimation, three parameters ( $\alpha$ and $\beta$ ) in equation (1), three 182 parameters $(\omega, \alpha, \beta)$ have further been used in equation (1), with distributions representing the AR 183 (1)-GARCH $(1,1)$ model. Moreover, $\omega$ shows the GARCH Using Log-Likelihood (L.L.), Akaike 184 Information Criterion (AIC), and the Bayesian Information Criterion (BIC), the model vigorous of 185 the recent study is analysed (Econ. Time Covid-19, 2020; Haroon \& Rizvi, 2020). The variables 186 used in the study include economic development, measured as GDP growth (annual \%) and used 187 as predictive variables, whereas green credit is used as a predictor and measured as the total green 188 credit of the banks/total loans of the banks. In addition, green investment and green securities are 189 also used as predictors and measured as the fiscal expenditure of industries/total fiscal expenditure, 190 total market value, and total market value of all shares. Finally, capital formation and government 191 educational expenditures are also used as predictors and measured as gross capital formation (\% 192 of GDP) and current education expenditure (\% of total expenditures), respectively. We used the 
193 194

195

model proposed by He et al. (2020), who concluded that the AR (1) - GARCH $(1,1)$ model was reliable for estimating the impact of COVID-19 fear on public attention to stock market volatility.

$$
\begin{gathered}
F i, t=g i, t \varepsilon i, t, \varepsilon i, t \sim R k T(u, \lambda) \\
H_{i t}=\omega_{i t}+\alpha \epsilon 2_{t-1}+\beta h i_{t-1}+\gamma e 2_{t-1}-e i_{t-1}
\end{gathered}
$$

Using these equations, the co-movement of the variables was established for operationalisation, and these results were robust with the GARCH method. With the complete disruption of the economy, government should focus more on expansionary fiscal policies to stimulate recovery. This mainly means to increase government spending, which will increase cash flow and liquidity of assets, thereby putting more money in the hands of citizens to encourage higher demand for goods and services. This, in turn, will increase the levels or volumes of supply in the economy. Wavelet coherence is an empirical framework used to examine the relationship between two or two variables. To justify the use of wavelet coherence, we used two series sequences called $\mathrm{x}(\mathrm{t})$ and $\mathrm{y}(\mathrm{t})$, which justify and clarify the function as

$$
W_{x y}(m, n)=W_{x}(m, n) W_{y}^{*}(m, n),
$$

Wherever the given wavelet transforms of $\mathrm{x}(\mathrm{t})$ and $\mathrm{y}(\mathrm{t})$ contribute in the objective function, for example, Wx $(\mathrm{m}, \mathrm{n})$ and $\mathrm{Wy}(\mathrm{m}, \mathrm{n})$, the wavelet index to evaluate as $\mathrm{n}$; therefore, the composite conjugate solution as the sign *.

$$
x(t)=\frac{1}{C_{\psi}} \int_{0}^{\infty}\left[\int_{-\infty}^{\infty} W_{x}(m, n) \psi_{m, n}(t) d u\right] \frac{d n}{N^{2}}, N>0
$$

Whereas

$$
\|x\|^{2}=\frac{1}{C_{\psi}} \int_{0}^{\infty}\left[\int_{-\infty}^{\infty}\left|W_{x}(m, n)\right|^{2} d m\right] \frac{d n}{N^{2}}
$$

Consequently, the wavelet transform is used as an empirical method to measure the non-stationary time series underlying variables (Lopez-Tiro et al., 2020). The wavelet transformation frame contains fluctuations from high to low and low to high and the frequency between underlying 
216 entities. The objective function in the cross-wavelet transforms can estimate the cross-wavelet

217 power between two variables in a series. The mathematical model and the coefficients of the 218 adjusted wavelet coherence are measured as,

$$
R^{2}(m, n)=\frac{\left|N\left(N^{-1} W_{x y}(m, n)\right)\right|^{2}}{N\left(N^{-1}\left|W_{x}(m, n)\right|^{2}\right) N\left(N^{-1}\left|W_{y}(m, n)\right|^{2}\right)}
$$

$220 \mathrm{R}$ characterises the mechanism of smoothing in wavelet transformation, whereas $0 \leq \mathrm{R} 2(\mathrm{~m}, \mathrm{n}) \leq$

2211 denotes the interval of the squared coefficients of wavelet coherence. A score of 1 indicates a

222 more vigorous correlation among the entities being measured, while the coefficients of wavelet

223 coherence smaller than a threshold are eradicated by thresholding the estimating parameter. The

224 hard threshold reduction objective function can be written as follows:

$$
x_{h t}=\left\{\begin{array}{ll}
0 i f|x| \leq & \lambda \\
x i f|x|> & \lambda
\end{array}\right\}
$$

226 Mid thresholding is used as a flexible technique, which ensures that the mid-level reduction in the

227 objective function is as follows:

$$
\begin{aligned}
& x_{h t}=\left\{\begin{array}{cc}
0 i f|x| \leq & \lambda \\
x-\frac{\lambda 2}{x} i f|x|> & \lambda
\end{array}\right\}, \\
& x_{y t}=\left\{\begin{array}{cc}
0 i f|y| \leq & \lambda \\
y-\frac{\lambda 2}{y} i f|y|> & \lambda
\end{array}\right\},
\end{aligned}
$$

230

231 The cross-wavelet transforms $x_{h t}$ and $x_{y t}$ can be described in the form of W.X.Y. = W.X.W.Y.*,

232 whereas W.X. and W.Y. characterise bi-transforms designed for wavelets X and Y, respectively.

233 The mixed debate $\left(W_{x y}\right)$ can be described as the original equivalent stage:

$$
D\left(\frac{\left|W_{n}^{X}(s) W_{n}^{Y_{*}}(S)\right|}{\sigma X \sigma Y}<p\right)=\frac{U \vartheta(p)}{\vartheta} \sqrt{P_{k}^{X} P_{k}^{y}}
$$


235 The level of assurance associated with the likelihood $\mathrm{p}$ and for density likelihood purposes is Uף 236 (p), explained through the square root of multiplication of two $\chi 2$ distributions. The Granger 237 causality (GC) incidence field is described to categorise the two series based on supernatural 238 interdependency. Breitung and Candelon (2006) demonstrated that the aforementioned test shows 239 the association between $\mathrm{x}$ and $\mathrm{y}$ in the VAR (p) mathematical model, as follows:

$$
x=a_{1} x_{t-1}+\cdots+a_{p} x_{t-p}+\beta_{1} y_{t-1}+\cdots+\beta_{p} y_{t-p}+\beta_{1 t}
$$

241 The null hypothesis was verified through the test proposed by Geweke (1992) in null linear 242 restriction, as follows:

\section{Results and Discussion}

\subsection{COVID-19 Fear Nexus with Public Attention}

In the first phase of the pandemic, we observed a long-term relationship between stock wave of COVID-19, after the general quarantine restrictions were relaxed following the first wave,

250 infections and deaths increased turmoil in the stock market and the entire economy and had a 251 significant impact on finances. Unemployment rose steeply during the pandemic for various 252 reasons, mainly the closure of many unessential businesses. This led to increased poverty rates 253 because people were not working, and their disposable income was significantly reduced, making 254 them unable to meet their tax burdens. Governments can ease this problem by increasing 255 unemployment benefits for people who have lost their jobs.

Table 1. Panel unit root test

\begin{tabular}{lllllc}
\hline Constructs & LLC & FADF & FPP & IPS & Stationary level \\
\hline COVID-19 RCI $_{\mathrm{t}}$ & 1.91 & 11.07 & 11.07 & 2.00 & - \\
$\Delta$ COVID-19 RCI & $-0.22 *$ & $32.14^{*}$ & $78.3 *$ & -0.10 & $1(1)$ \\
\hline
\end{tabular}




\begin{tabular}{llllll}
\hline COVID-19 RDI $_{\mathrm{t}}$ & 2.75 & 9.00 & 3.19 & 0.12 & - \\
$\Delta$ COVID-19 RDI $_{\mathrm{t}}$ & $-13.51^{*}$ & $71.75^{*}$ & $22.09 *$ & $-7.34 *$ & $1(1)$ \\
COVID-19 GFI & 4.66 & 3.20 & 5.49 & 0.99 & \\
$\Delta$ COVID-19 GFI $_{\mathrm{t}}$ & $-1.00^{*}$ & $86.01 *$ & $34.29 *$ & $-1.38^{*}$ & $1(1)$ \\
MA $_{\mathrm{t}}$ & 5.09 & 4.80 & 4.73 & 1.20 & \\
$\Delta$ MA $_{\mathrm{t}}$ & $-2.17 *$ & $60.12^{*}$ & $24.4 *$ & $-2.27 *$ & $1(1)$ \\
MA-CC $_{\mathrm{t}}$ & $11 . .50$ & $32.11^{*}$ & $49.50 *$ & 6.18 & \\
$\Delta$ MA-CC $_{\mathrm{t}}$ & $-3.07 *$ & $20.00 *$ & $27.12 *$ & $-3.13 *$ & $1(1)$ \\
MA-POL $_{\mathrm{t}}$ & 5.19 & 28.08 & 28.08 & 4.01 & \\
$\Delta$ MA-POL $_{\mathrm{t}}$ & $-0.04 *$ & $40.01 *$ & $72.34 *$ & -4.67 & $1(1)$ \\
\hline
\end{tabular}

Note: LLC, Levin-Lin-Chu test; FADF, Fisher-augmented Dickey-Fuller test; FPP, Fisher Phillips-Perron test; IPS, Im-Pesaran-Shin test; * denotes significance at the 5\% level. Source: Authors' calculations using R-Studio 10 software.

Our empirical findings on the nexus of COVID-19 fear and public attention to the environment extended their reporting using the unit root test and ARDL technique (see table 1). The study results were stationary at $l(1)$. The economy can recover mainly through geographical subsidies to encourage firms to invest in depressed areas, such as the agricultural sector. This means that a return shock in one economy will only have a short-term impact on other markets. The time domain effect to use the return spillover effect shows that NASDAQ $(0.608 \%)$ paid the most to CRIA, followed by Cyprus (0.304\%), DAX (0.247\%), and SP500 (0.247\%) (0.146\%). This shows the pandemic had a significant influence on the returns of major stock exchange stock markets. We can see that SP500 revenue overflow was the largest (6.089\%), SP500's DAX revenue overflow is the largest $(30.795 \%), \mathrm{S} \& \mathrm{P} 500$ is the largest $(21.428 \%)$, and DAX returns from SP500 (21.428\%). (31.036\%). This sector has been significantly affected by the pandemic, with reduced commodity prices and a lack of labour. Firms can be given subsidies for taking on long-term employees; for example, they can be given income tax breaks or tax holidays to sustain their economic activities (Okorie \& Lin, 2020). Moving window research showed that the impact 
274 of COVID-19 on stock market instability was greater than that of the 2008 global financial crisis.

275 During the COVID-19 pandemic, government-authorised non-profit organisations took many

276 steps, including reducing travel abroad, closing classrooms, implementing mandatory lockdowns,

277 banning public meetings, closing unnecessary businesses, and ordering the use of masks. These

278 interventions had a direct impact on economic growth, leading to falling energy prices and four

279 times the loss of stock exchange circuit breakers, resulting in significant losses for investors over

280 a brief period of time.

281 Table 2. Autoregressive distributed lag (ARDL) test

\begin{tabular}{lllll}
\hline Variable & Coefficient & Std. Error & t-Statistic & Prob.* \\
\hline C & $40.11^{*}$ & 29.85 & 4.13 & 0.000 \\
COVID-19 RCI & $8.47^{*}$ & 15.00 & 2.75 & 0.000 \\
COVID-19 RDI & $10.34^{*}$ & 29.25 & 6.67 & 0.003 \\
COVID-19 GFI & $19.55^{*}$ & 0.006 & 4.48 & 0.001 \\
MA & $31.12^{*}$ & 67.04 & 4.09 & 0.000 \\
MA-CC & $16.47^{*}$ & 0.201 & 2.77 & 0.000 \\
MA-POL & $25.33^{*}$ & 0.572 & 0.52 & 0.000 \\
\hline R-Square & 0.51 & Mean dependent variance & 1.30 \\
Adjusted R-Square & 0.38 & S.D. dependent variance & 72.81 \\
Standard error & 14.21 & Akaike info criterion & 8.01 \\
Log L.H. & -299.36 & Hannan-Quinn Criterion & 6.35 \\
Prob (F-statistic) & 0.010 & Durbin Watson & 1.97 \\
\hline
\end{tabular}

Source: Authors' calculation

Table 2 shows that COVID-19 fear indices, such as RDI, GFI, and RCI, had a positive 284 relationship with public attention to media stock exchange return variation at a p-value $<0.05$. US 285 economic policy uncertainties increased owing to US geopolitical risk fluctuations, causing 286 volatility in COVID-19 and oil prices. However, only a 3.1\% increase in power consumption will 287 occur. The end of 2020 is more likely to have a moderate impact on the energy sector. The results 288 show that the average return rate was $25.32 \%$, which is less than the total correlation degree 
289 variance of $40.11 \%$ (for constant), indicating that the return rates of stock exchange index

290 volatilities in the world are closely related to their respective volatility. The results show that the

291 short-term volatility (S\&P, 0.0024) had the largest total return spillover, whereas NASDAQ

292 (0.0118) had the largest long-term return, and the others were as follows: DOW (90.0056), DAX

293 (0.0456), CRIA (0.0026), and Cyprus (0.0016). COVID-19 affected industrial productivity,

294 directing a substantial decrease in electricity consumption in China. Although research by ICIS

295 China suggested that low levels were to be expected until April 2020, a capacity below 10\% was

296 served for knitting machines in textile factories, making it the lowest in the last five years. China

297 is the world's largest exporter of textiles and clothing. For example, with a two-tier pricing

298 structure (for example, first and second tiers), a crude oil company can (i) independently ration,

299 i.e. increase the price of the first shortage of crude oil without changing the price of the second

300 shortage during the same period to satisfy the market.

301 Table 3. Robustness test

\begin{tabular}{lllllll}
\hline Variable & Coefficient & SE & T-stats & Sig. & Pseudo R & Sparsity \\
\hline$\tau=10^{\text {th }}$ & & & & & & \\
COVID-19 RCI & $3.24^{*}$ & 4.18 & 1.58 & 0.000 & 0.88 & 1045.12 \\
COVID-19 RDI & $1.69^{*}$ & 0.89 & 0.33 & 0.017 & & $(0.000)$ \\
COVID-19 GFI & $1.56^{*}$ & 0.75 & 0.46 & 0.000 & \\
MA-CC & $0.76^{*}$ & 0.15 & 0.89 & 0.027 & \\
MA-POL & $0.39^{*}$ & 0.27 & 0.66 & 0.014 & \\
C & 107.99 & 111.83 & 0.65 & 0.011 & \\
$\tau=25^{\text {th }}$ & & & & & \\
COVID-19 RCI & $3.03^{*}$ & 1.11 & 1.08 & 0.040 & 0.72 & \\
COVID-19 RDI & $1.05^{*}$ & 0.57 & 0.99 & 0.028 & \\
COVID-19 GFI & $0.98^{*}$ & 0.77 & 0.20 & 0.000 & \\
MA-CC & $0.67^{*}$ & 0.90 & 0.22 & 0.001 & \\
MA-POL & $0.89^{*}$ & 0.63 & 0.01 & 0.003 & \\
C & 123.74 & 217.01 & 0.85 & 0.000 &
\end{tabular}




\begin{tabular}{lllllll}
\hline$\tau=50^{\text {th }}$ & & & & & & \\
COVID-19 RCI & $4.18^{*}$ & 3.13 & 4.44 & 0.000 & 0.82 & 1066.89 \\
COVID-19 RDI & $3.99^{*}$ & 2.47 & 3.11 & 0.025 & & $(0.000)$ \\
COVID-19 GFI & $2.02^{*}$ & 2.59 & 0.01 & 0.039 & & \\
MA-CC & $1.25^{*}$ & 0.63 & 0.79 & 0.020 & & \\
MA-POL & $4.09^{*}$ & 0.20 & 0.65 & 0.027 & & \\
C & 167.34 & 202.87 & 0.77 & 0.010 & & \\
$\tau=75^{\text {th }}$ & & & & & & \\
COVID-19 RCI & $6.42^{*}$ & 0.67 & 3.18 & 0.040 & 0.89 & \\
COVID-19 RDI & $5.01^{*}$ & 0.24 & 0.10 & 0.001 & & \\
COVID-19 GFI & $2.76^{*}$ & 0.01 & 0.37 & 0.035 & & \\
MA-CC & $0.64^{*}$ & 0.73 & 0.03 & 0.019 & & \\
MA-POL & $0.78^{*}$ & 0.41 & 0.09 & 0.011 & & \\
C & 101.34 & 105.26 & 0.25 & 0.008 & & \\
$\tau=90^{\text {th }}$ & & & & & & \\
COVID-19 RCI & 11.29 & 3.00 & 7.37 & 0.007 & 0.74 & \\
COVID-19 RDI & $5.77^{*}$ & 2.65 & 0.29 & 0.000 & & \\
COVID-19 GFI & $6.22^{*}$ & 2.15 & 0.00 & 0.000 & & \\
MA-CC & $1.47^{*}$ & 1.01 & 0.84 & 0.026 & & \\
MA-POL & $1.80^{*}$ & 0.20 & 0.13 & 0.027 & \\
C & 70.01 & 89.08 & 0.86 & 0.000 & \\
\hline
\end{tabular}

303 Table 3 presents the robustness test. In contrast to the return spillover effect in frequency 304 dynamics, an absolute volatility spillover occurred in the long-term, medium-term, and short-term 305 frequency dynamics. Furthermore, a sudden increase in stock market volatility was observed in 306 mid 2020 due to the COVID-19 pandemic. More specifically, COVID-19 would have an impact 307 of nearly $80 \%$ on stock market volatility in 2020 , which is almost the same as the impact of the 3082008 global financial crisis. Reduce the amount of crude oil that meets the primary price to reach 309 consumers with medium demand levels or (iii) increase the first-level rate by $15 \%$ (from $\$ 1.943$ 310 per barrel to $\$ 2.321$ ), and the second-level rate increases by $43 \%$ (from $\$ 2.78 /$ barrel to $\$ 4.53$ ). 
311 This policy will have the least impact on the welfare of low-demand households that consume less

312 than 24 barrels per billing cycle. For users with more than 3028 barrels per billing cycle, the

313 marginal crude oil rate will increase by $43 \%$ and increase by $78 \%$ (from $\$ 2.768$ to $\$ 3.76$ for 1 -

314 barrel consumption). Furthermore, uncertainty avoidance is a measure that tests how accepting a

315 culture is to unpredictable consequences in the stock market. At the end of week three following

316 the first outbreak declaration, countries with high individualism scores underwent a $12.71 \%$ lower

317 stock price recession than countries with low individualism scores. Furthermore, we discovered

318 that countries with higher uncertainty avoidance scores experienced a $5.40 \%$ greater stock price

319 decline than those with poor uncertainty avoidance scores during the same time span. Greater stock

320 price reductions are correlated with greater stock return volatility. In particular, within the first

321 several weeks of the pandemic, countries with low individualism and strong ambiguity resistance

322 had higher instability as well as larger price declines. The private sector, including small business

323 enterprises with a low recovery period (Asif et al., 2020; Sarker et al., 2020; Iram et al., 2020;

324 Tehreem et al., 2020), emphasised that the government should use import substitution or boost

325 domestic consumer and production goods production. The results of our calculation showed a

326 negative association between stock market returns and COVID-19 cases. The rise in the rate of

327 COVID-19 caused a sudden decline in stock market returns (short-and long-run direct effects).

328 Furthermore, it can be illustrated that negative spillover consequences, along with a rise in 329 government reaction strength, causes stock market returns in similar countries to decline (short330 and long-run indirect effects). Overall, spillover results aggravated the detrimental influence of 331 lockout interventions on the stock market. The finding that spillover effects are greater than direct 332 effects is an outstanding outcome of our study. Although it can seem counterintuitive, because of 333 the accumulated spillover effects across multiple cross-sectional units, this is not unusual. 


\subsection{COVID-19 Fear Nexus with Stock Market Volatility}

Although the current financial crisis players doubt the perseverance of a subsequently excellent ratio of profit, while a breakeven point bottommost of $7 \%$, which recommends that the implementation scenario of the market flooding is questionable, it can concisely be stated that the exchange rates at the beginning of the study period (September 2014), for sanctions, both at the beginning or during the study period, positive co-movement between gold prices and foreign exchange rates was observed. In comparison, the foreign exchange rate was the most significant variable. The results are aligned with the report by Anser et al. (2020d). Over time, a significant decrease in the degree of co-movement between these three variables became prominent. However, investors faced significant gold market losses owing to government interventions in foreign exchange, even the people. No significant co-movement between foreign exchange, gold markets, and stock markets was observed, even after the outbreak. Stock market investors are likely to get with the help of an analysis related to exchange rates. Nevertheless, as the crisis evolves, co-movement analysis will no longer help investors interested in investing in the stock market. Although stock markets with foreign investors are vulnerable to the international shock caused by COVID-19, the long-term outlook for them is positive based on the geographical diversification of these countries. While holding foreign investment would indicate a more concrete international presence, the extent of COVID-19 for all stock markets with foreign revenue and foreign assets. We observed a negative relationship between these variables in the short run and the COVID-19 impacted economies, whereas long-term investors have more opportunities to invest in the long term during a recession. The post-COVID-19 scenario may entice a strong recovery in the stock market, and there is therefore a great opportunity for investors to enjoy capital gains and dividends. 


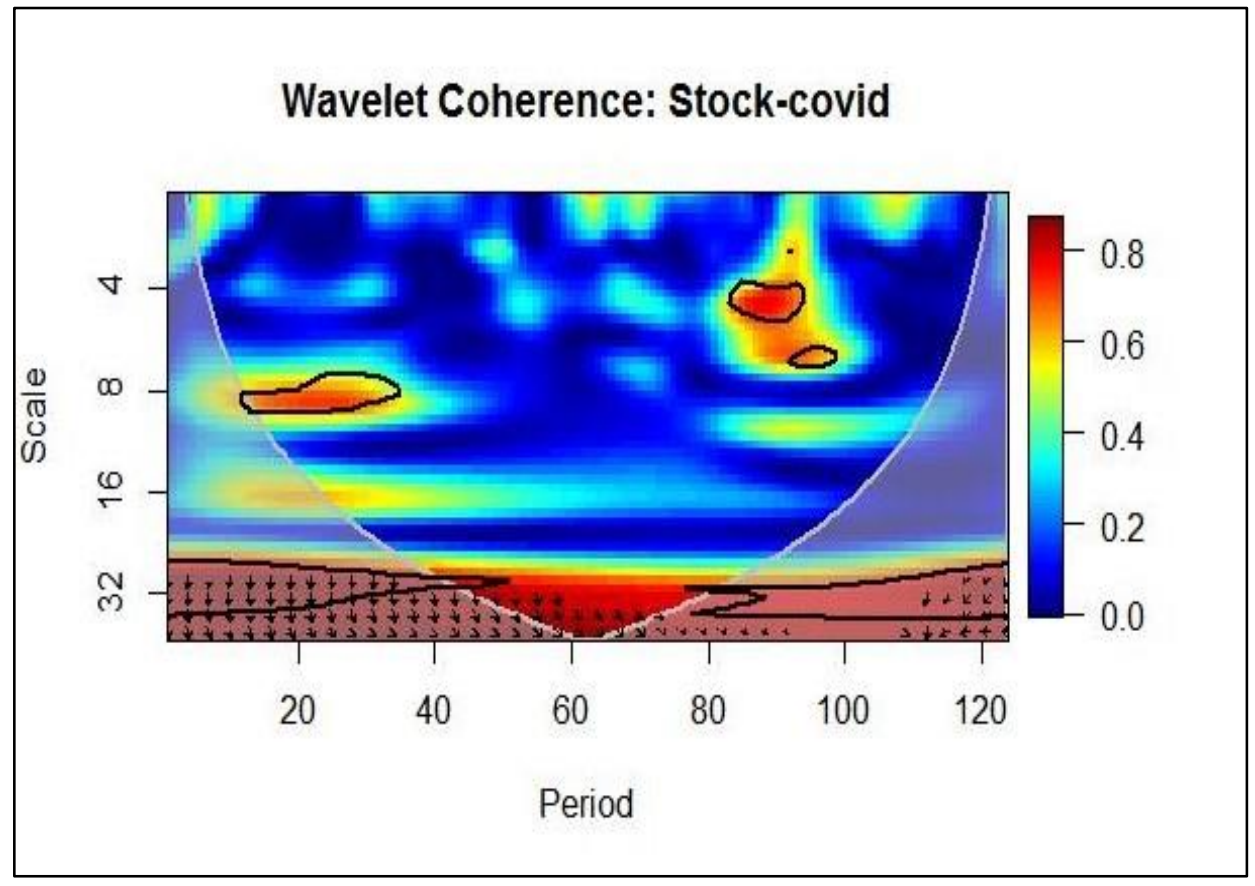

Figure 1. Wavelet coherence between stock return and COVID-19 cases

In Figure 1, we first observe the wavelet coherence of each pair of variables during the first wave of the COVID-19 outbreak, and then find that there are many important co-movements between COVID-19 cases and stock performance. The large island in Figure 1 confirms a severe dependence on short-term frequency bands at the beginning, centre, and end of the first COVID19 wave cycle. The wavelet coherence confirmed COVID-19 cases, and S\&P500, NASDAQ, DAX, DOW, and Cyprus showed severe dependence at the beginning of the first fluctuating cycle. In the short term, Figure 1 shows another island in the top right corner, where the co-movement between these two variables is higher at the end of the wave. The small island in the left centre of

367 Figure 1 shows that the reported cases are countercyclical associations with stock performance. 368 Economic growth is higher with higher trade openness and education rates and lower due to higher 369 government consumption and inflation. Simultaneously, a drop-in oil prices is observed. Our 370 findings are consistent with those of Huynh et al. (2020) and Feng et al. (2020). 
Production and promoting processes were also affected by COVID-19 because they require

372 local physical contact (Yousaf et al., 2020; Tehreem et al., 2020; Wasif Rasheed \& Anser, 2017;

373 Xu et al., 2020). Just as the digital economy produces many roles, it also destroys others (Ikram et

374 al., 2019; Shah et al., 2019). NASDAQ and CRIA faced a 65\% and 57\% declining stock market

375 volatility trend, respectively. In contrast, DAX declined around 17\%, S\&P (500) around 31\%,

376 Cyprus SE around 24\%, and NASDAQ around 28\%. Since the COVID-19 outbreak, the DOW has

377 faced a V-shaped curve in different periods for a short time during the study period. The economic

378 implications show that the time-varying conditional correlations shows that between the two

379 markets has changed greatly, which means that investors will regularly change their portfolio

380 structure during the volatility. The positive dynamic conditional correlation between stock markets

381 supports the existence of contagious (due to extreme vases of COVID-19) effects. As a result,

382 during the COVID-19 crisis, many risk spillovers occurred between the stock markets. The market

383 changes over time and is unpredictable, which means that a portfolio manager cannot adjust their

384 portfolio structure during a period of crisis. The unit root test was applied, showing stationary

385 matter of the data, and all the study constructs were found to fit at the first difference (see Table

386 4). The AR (1) - GJR $(1,1)$ model provided certain fascinating insights. The intercept $(\beta 0)$ and

387 mean coefficient $(\beta 1)$ of the stock market volatility index equated with each sample market relative

388 and near zero. The findings show an asymmetrical impact of COVID-19 on selected stock

389 markets, which was consistent with the work done by coming up with an input package (Mohsin

390 et al., 2018b; 2021).

391 Table 4. Effects of Covid-18 on stock market volatility

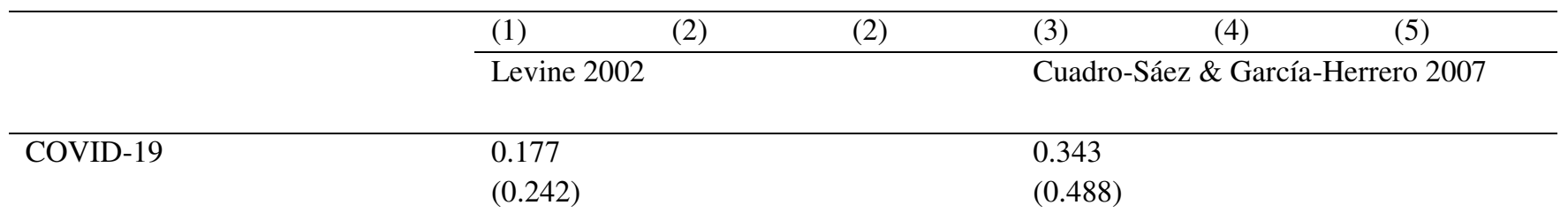




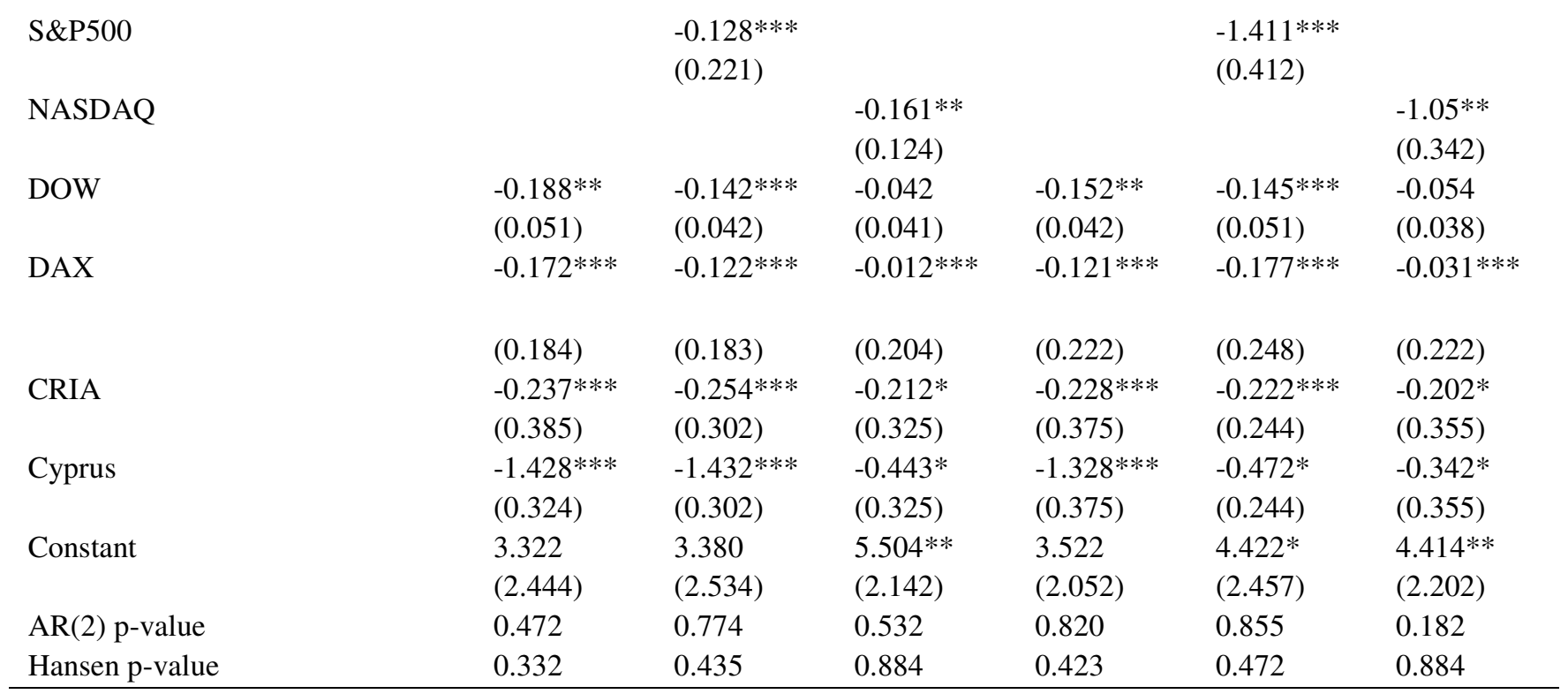

392

393

394

395

396

397

398

399

400

401

402

403

404

405

406

407

The relationship between stock market volatility and the COVID-19 pandemic has directly affected stock returns. The results in Table 4 show that almost all stock exchange returns were negatively associated with the number of COVID-19 cases during this period; for example, a $1 \%$ increase in COVID-19 cases caused a $12.8 \%$ decrease in S\&P 500, -0.161 in NASDAQ, variation in DOW from -0.188 to -0.054 , and variation in DAX from -0.172 to -0.012 . The CRIA was the stock exchange most affected by COVID-19; for example, a 1\% increase in COVID-19 caused a $23.7 \%$ decrease in stock returns. Throughout the pandemic, the logarithm of GDP was taken as a control variable. The table shows the econometric estimation and results of COVID-19 and stock market volatility. Almost all stock market returns had a negative relationship with COVID-19 cases, indicating that they were near zero during the COVID-19 period. These findings suggest that the markets were facing less volatility during the pandemic period, caused by global COVID19 outbreak fear (L. Sun et al., 2020b; H. Sun et al., 2020; L. Sun et al., 2020a). The GARCH coefficient $(\omega)$ for the Shanghai SE is great by means of a substantial margin, and the rest of the markets were observed using reasonably small GARCH coefficients. Disruptions in world trading are expected to have a major effect on stock markets. COVID-19 is projected to result in a 14- 
$32 \%$ decrease in stock exchange and a 30-40\% decrease in foreign direct investment in 2022 if

409 the same trend continues. In 2020, multinational corporations also reduced their foreign investment

410 by $20-30 \%$. Only government efforts to bring trade chains back home are expected to boost these

411 estimates. COVID-19, while professionals and policymakers signal the culmination of

412 globalisation because it illustrates the costs of significant dependence on other economies, adding

413 to the current spillover impact. Others contend that the effects of COVID-19 will be fleeting, and

414 that turning trade inwards will not help countries weather the crisis.

Table 5. Unit root test

\begin{tabular}{lcc}
\hline Constructs & \multicolumn{2}{c}{ First-order differences } \\
\hline RCI & $-1.22(3)$ & $-6.66(2)^{*}$ \\
RDI & $-1.29(3)$ & $-6.70(1)^{*}$ \\
GFI & $-1.28(3)$ & $-6.55(2)^{*}$ \\
SMVI & $-1.24(3)$ & $-6.59(2)^{*}$ \\
\hline
\end{tabular}

Source: Authors' calculation

418 Shanghai, and NASDAQ correlated significantly with the global fear index of COVID-19. The 419 coefficients of the study were significant at a p-value of 5\%. Surprisingly, the Shanghai Stock 420 Exchange and DAA had a larger coefficient. The volatility coefficients of all sample international 421 stock exchanges were also statistically significant at the 5\% level (table 5). However, this indicates 422 that the international stock markets' volatility index co-moved with the global fear index of the 423 COVID-19 outbreak. The COVID-19 pandemic has also had an effect on the global economy, as 424 stock market indexes have been shut down. The resulting financial turmoil can be seen in the 425 movements of various stock market indexes. The S\&P500, DAX, DOW Average, and NASDAQ 426 indexes in the United States (US) both dropped significantly before the government enacted the 427 Coronavirus Assistance, Relief, and Economic Protection Act, during which the three indices 
428 increased for specific periods by 7.3\%, 17.73\%,2 and 7.33\%, 3\%, respectively. Furthermore, the 429 yield on a 10-year US Treasury Bond fell to $0.67 \%$. Several new studies have analysed and 430 validated the COVID-19 pandemic's drastic effects on stock markets.

431 Table 6. AR (1) - GJR $(1,1)$ model estimates ${ }^{1}$

\begin{tabular}{|c|c|c|c|c|c|c|}
\hline & S \& P (500) & NASDAQ & DOW & DAX & CRIA & Cyprus \\
\hline \multirow[t]{2}{*}{$\mathrm{C}_{0}$} & $-0.0215^{*}$ & $-0.0271^{*}$ & $-0.0196 *$ & $-0.0393^{*}$ & $-0.0299 *$ & $-0.0118 *$ \\
\hline & $(0.000)$ & $(0.000)$ & $(0.000)$ & $(0.000)$ & $(0.000)$ & $(0.000)$ \\
\hline \multirow[t]{2}{*}{$\mathrm{C}_{1}$} & $0.0024^{*}$ & $0.0118 *$ & $0.0056^{*}$ & $0.0459 *$ & $0.0026^{*}$ & $0.0016^{*}$ \\
\hline & $(0.000)$ & $(0.000)$ & $(0.000)$ & $(0.000)$ & $(0.000)$ & $(0.000)$ \\
\hline \multirow[t]{2}{*}{$\Omega$} & $0.0005^{*}$ & $0.0001 *$ & $0.0011 *$ & $0.0058^{*}$ & $0.0036^{*}$ & $0.0000 *$ \\
\hline & $(0.000)$ & $(0.000)$ & $(0.000)$ & $(0.000)$ & $(0.000)$ & $(0.000)$ \\
\hline \multirow[t]{2}{*}{ A } & $0.0351 *$ & $0.0642 *$ & $0.0222 *$ & $0.0788^{*}$ & $0.0494 *$ & $0.0205^{*}$ \\
\hline & $(0.000)$ & $(0.000)$ & $(0.000)$ & $(0.000)$ & $(0.000)$ & $(0.000)$ \\
\hline \multirow[t]{2}{*}{ B } & $0.5634 *$ & $0.2228 *$ & $0.2188^{*}$ & $0.6749 *$ & $0.5221 *$ & $0.2017 *$ \\
\hline & $(0.000)$ & $(0.000)$ & $(0.000)$ & $(0.000)$ & $(0.000)$ & $(0.000)$ \\
\hline \multirow[t]{2}{*}{$\Gamma$} & $0.2701 *$ & $0.3600 *$ & $0.1212^{*}$ & $0.4964 *$ & $0.3903 *$ & $0.1918 *$ \\
\hline & $(0.000)$ & $(0.000)$ & $(0.000)$ & $(0.000)$ & $(0.000)$ & $(0.000)$ \\
\hline \multirow[t]{2}{*}{ Y } & $2.26^{*}$ & $2.09 *$ & $2.11 *$ & $2.87 *$ & $2.40 *$ & $2.22 *$ \\
\hline & $(0.000)$ & $(0.000)$ & $(0.000)$ & $(0.000)$ & $(0.000)$ & $(0.000)$ \\
\hline \multirow[t]{2}{*}{$\Lambda$} & $-0.7087^{*}$ & $-0.0169 *$ & $0.2333^{*}$ & $-0.6945^{*}$ & $0.4404^{*}$ & $0.0592 *$ \\
\hline & $(0.000)$ & $(0.000)$ & $(0.000)$ & $(0.000)$ & $(0.000)$ & $(0.000)$ \\
\hline$L L$ & 1245.11 & 354.58 & 101.00 & 726.08 & 404.52 & 116.56 \\
\hline$A I C$ & -3127.04 & -220.77 & -60.55 & -313.27 & -197.40 & -100.11 \\
\hline$B I C$ & -3101.87 & -394.45 & -156.33 & -1559.74 & -1785.09 & -131.31 \\
\hline
\end{tabular}

432 433 434 435 436 437 438

${ }^{1}$ Here presented model about four markets followed Skewed t distribution regarding calculations.

$\mathrm{C}_{0}$ is the constant factor, $\mathrm{C} 1$ is the COVID-19 fear index, $\mathrm{Y}$ is the dependent variable of study, $\beta$ is the coefficient of the variance equation for the study stock market volatility index, $v$ is the level of autonomy parameter that equates to 2 for every market, $\lambda$ is the asymmetry or skewness parameters, $\Gamma$ is the AR (1) estimation parameter, $\Lambda$ and $\Omega$ are the GJR $(1,1)$ estimation parameters.

The $\beta$ coefficient of the variance equation for the study stock market volatility index was also significant at the $5 \%$ level (see table 6). The proposed outcomes recommended for 
marketplace volatility index variance for all international stock markets, with the exclusion of the 440 S\&P500, were deeply co-moved by the global fear index (GFI) of the COVID-19 outbreak. The 441 autonomy parameter $v$ equates to 2 for every market except the S\&P500 index. A 'sharp-V' 442 recovery feature also characterises the German economy. This means that the economy fell 443 sharply, and it regained its form instantly. This shape economically implies a rapid loss and regain 444 in employment pattern, gross domestic product, and industrial output rate. Finally, the economy, 445 that is why it has adopted heavy penalties on citizens who fail to abide by face mask laws (50 446 euros). Therefore, from the strategies mentioned above for the country, it has been outlined that 447 the Dutch economy will first shrink by $11 \%$ and will later expand rapidly and become more robust 448 than before. Compared with the overall return spillover results, Table 7 shows that the long-term 449 frequency of volatility frequency is 0.7429 , which has the largest total volatility spillover rate, 450 followed by mid-term volatility $(0.049 \%)$ and short-term volatility $(0.297 \%)$, indicating the impact 451 of each market transaction on volatility spillover. More importantly, the NASDAQ (28.433\%) 452 increased the most volatility spilled over to day trading during the peak period of COVID-19 cases, 453 followed by S\&P500 (7.384\%), DAX (4.574\%), and DOW (4.435\%). This finding indicates that 454 the volatility spillover effect between COVID-19 cases and stock market returns was greater than 455 the income spillover effect. At the same time, the S\&P500 had the largest volatility spillover from 456 DAX (24.556\%), DOW had the largest volatility impact from S\&P500 (38.195\%), and Cyprus had 457 the largest volatility impact from S\&P500 (46.901\%).

458 Table 7. GARCHX estimation for robustness for GFI and SMVI co-movement

\begin{tabular}{ccc}
\hline & Mean Equation & Variance Equation \\
\hline C & 0.037 & --- \\
Stock Market Volatility Index & $(0.21)$ & \\
& $-0.7429^{*}$ & -- \\
\hline
\end{tabular}




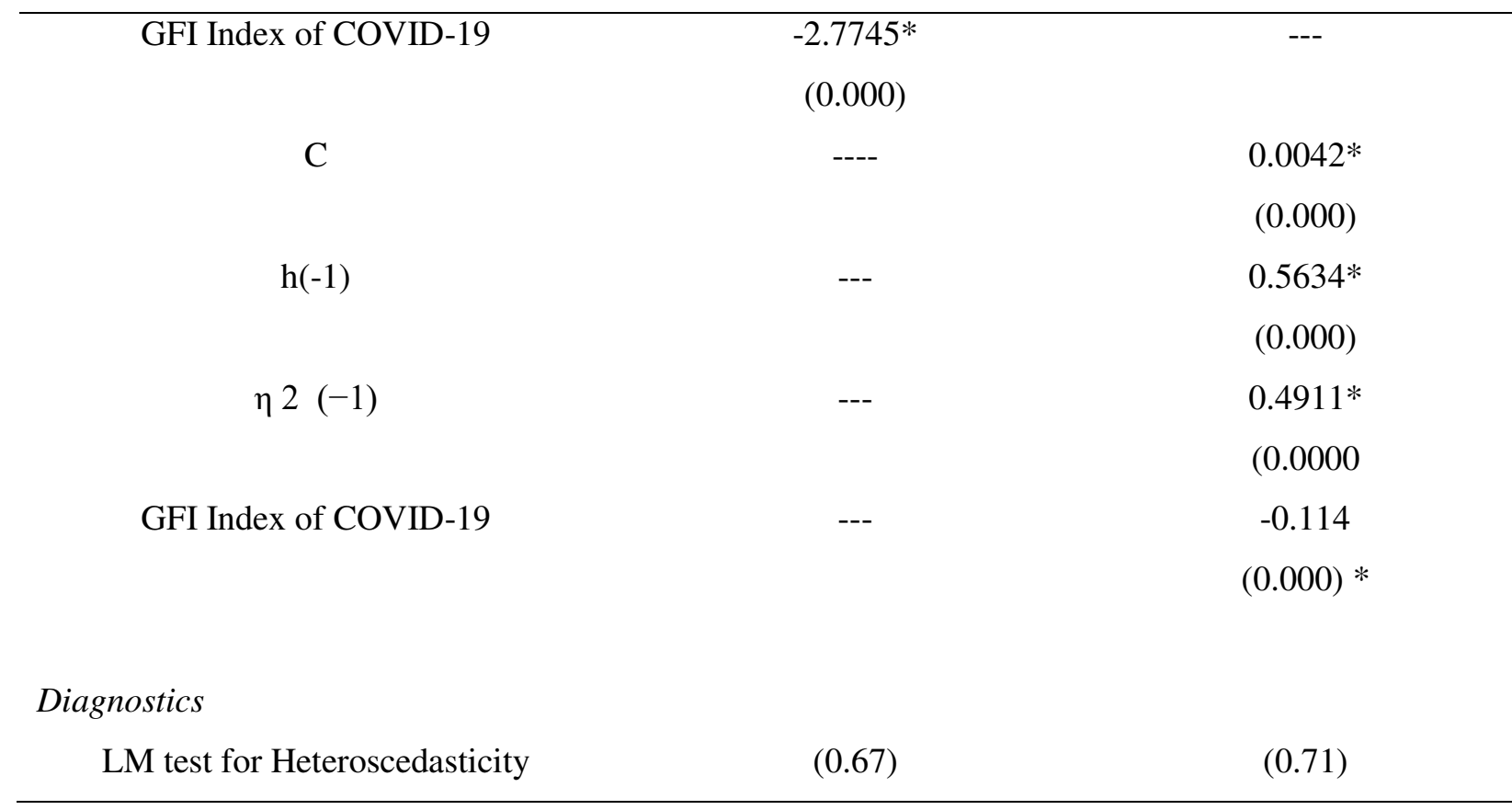
Source: Authors' calculation.

460 (i) There is a cyclicality between COVID-19 cases and stock exchange return volatility, 461 indicating that, in many countries, the average daily COVID-19 had a significant impact on the 462 volatility of stock exchange returns; (ii) the strong association between COVID-19 cases and stock 463 exchange return volatility indicates that COVID-19 cases had a significant long-term impact on 464 the stock market gains in selected countries; (iii) the low frequency and strong connectivity 465 indicate that COVID-19 cases had a strong co-movement with stock returns. The robust findings 466 from the GARCHX table showed that all the coefficients of conditional variance were 467 econometrically significant at the 5\% significance level. This fostered acceptance of the alternative 468 hypothesis that the coefficient of the variance equation was not zero. European countries have 469 witnessed rapid economic recovery during the pandemic. It was later indicated that thorough 470 improvements to the Dutch economy were necessary, and, indeed, good results were shown in the 471 last quarter of 2020. Despite the loss experienced through the total deaths worldwide, the economy 472 was saved. 

recommendations, such as social distancing, working from home, and protective gear for citizens.

475 The economic recovery plan is based on three aspects. The short-term recovery period: This 476 package aims to provide a stimulus stipend worth 130 billion Euros. The aim is to soften the 477 recession period and boost post-COVID-19 consumption. With this stipend in the roll-out, the 478 economy is expected to get back on track by the end of 2022, possibly a bit earlier. In addition, it 479 provides confidence to German citizens for future recovery.

\section{Conclusion and Policy Implications}

The rapid spread of the coronavirus disturbed global production and supply chains. The impact of COVID-19 triggered new planning and strategies for the future. The relationship between production and consumption was devastated, which caused an eruption during the

484 pandemic. We used the $\mathrm{AR}(1)-\operatorname{GARCH}(1,1)$ model, as it is reliable for estimating the impact 485 of COVID-19 fear on public attention to stock market volatility. The study also used wavelet coherence to measure the relationship between COVID-19 and stock market returns. Waveletbased techniques helped to classify lead-lag interactions in the time-frequency domain, thereby stock crash showed a $26 \%$ reduction over four consecutive days. The massive sudden decrease in the stock market index caused the US GDP to fall by about $4.8 \%$ and $20 \%$ during the first quarter 491 of 2020. According to our findings, the volatility of the stock market was lower in countries with 492 more COVID-19 cases. In the univariate and multivariate models, the robustness test results held. 493 In addition, the pandemic had a major indirect impact on stock performance. Stock returns seemed 494 very low within a few weeks after countries-imposed lockdowns. NASDAQ and CRIA faced a $49565 \%$ and $57 \%$ decline in stock market volatility, respectively, while DAX declined around 17\%, 
S\&P500 around 31\%, Cyprus SE around 24\%, and NASDAQ around 28\% due to the pandemic.

497 Furthermore, we found that S\&P500, Cyprus, CRIA, DOW, Shanghai, and NASDAQ correlated 498 significantly with the investor's global fear index of COVID-19.

499 A summary of the findings shows that the performance of the stock market and GDP growth 500 significantly decreased because of the pandemic, i.e., a $1 \%$ increase in the COVID-19, the stock 501 return, and GDP decrease with a $0.8 \%, 0.56 \%$, respectively. Investors' uncertainty in the capital 502 market and economic downturns negatively affected markets' stock market performance. On the 503 other hand, the lockdowns and the reduced number of tourists reduced energy consumption and 504 diminished GHG emissions, which is good news for the environment. However, when economies 505 enter the new everyday life, the required policies need to be implemented to achieve 506 environmentally sustainable healing. Therefore, this study investigated the impact of COVID-19 507 fear on public attention to stock market volatility and discussed the environmental effects. 508 Although the March 2020 COVID-19 stock crash was considered a significant decrease in the 509 stock market, the stock exchange market showed a $26 \%$ reduction over four days. The massive 510 reduction in stock exchanges caused the US GDP to decrease by $4.8 \%$ during the first quarter of 5112020 and the unemployment rate to decrease by $20 \%$.

512 Our results showed that the increase in confirmed cases and deaths caused by the coronavirus 513 was related to a significant decline in market liquidity and stability. Then, the market rebounded, 514 to a certain extent. To minimise the impact of external shocks on the markets, primarily in 515 emerging capital markets, policy measures are required, including market monitoring, to monitor 516 market price trends and the availability and liquidity of capital, and deregulation. Market function: 517 To ensure the continued, orderly, and fair function of the securities market for stocks, bonds, funds, 518 and other products. Issuer disclosure: To promote timely and accurate disclosure of vital 
519 information to ensure market transparency. Developing fiscal policies, such as cutting taxes and

520 interest rates, is recommended to increase aggregate demand and increase people's purchasing

521 power. These policies will allow people to borrow money at subsidised interest rates and increase

522 demand to foster recovery during the post-COVID-19 economic distress. Governments can

523 implement educational reforms to reduce structural unemployment by adopting new and improved

524 skills after the COVID-19 pandemic. For instance, it is recommended to use technology in 525 industrial-intensive industries, such as online teaching in schools and workplaces. However, while 526 remaining at home, the public paid much attention to COVID-19 news. Such attention to media is 527 reportedly another cause of COVD-19 pandemic fear (Topcu \& Gulal, 2020; Ashraf, 2020b).

528 In conclusion, the economic recovery of economies in the post-COVID-19 period can be

529 achieved through mixed fiscal and monetary policies to establish high levels of liquidity and add 530 to citizens' purchasing power, thereby increasing the overall consumption and aggregate demand 531 of individuals. Human capital is irreplaceable, as there is no substitute for the human brain's 532 decision-making capabilities. The progress of artificial intelligence (AI) made in this field is not 533 comparable to the originality and capabilities of the human mind. Therefore, to recover, economies 534 must first heal their human capital/populations with solutions to the spread of the coronavirus in 535 terms of better health care and quicker and safer vaccines and protective gear.

536 Another essential part is the micro-, small-, and medium-sized enterprises (MSMEs), which 537 shape over $50 \%$ of the economies in many countries. Supporting MSMEs through credit guarantee 538 schemes, low-interest loan programs, and tax cuts, especially during the COVID-19 pandemic, 539 could have multiple advantages for recovering from the economic recession, creating jobs, and 540 decreasing imports. Considering the challenge of controlling the pandemic, how and when the 541 COVID-19 crisis will end will determine the parameters of different policy responses. 
Ethical Approval and Consent to Participate: The authors declare that they have no known competing financial interests or personal relationships that seem to affect the work reported in this article. We declare that we have no human participants, human data or human tissues.

\section{Consent for Publication:}

N/A

Author Contribution: Yousaf Latif: Conceptualization, Data curation, Methodology, Writing original draft. Shunqi Ge: Data curation, Visualization, supervision Muhammad Ramzan: Visualization, editing. Wasim Iqbal: review \& editing. Salman Ali, Shahid Bashir: Writing review \& editing, and software

Funding: This research did not receive any specific grant from funding agencies in the public, commercial, or not-for-profit sectors.

Competing interest statement: The authors declare no conflict of interest.

Availability of data and materials: The data can be available on request

\section{Reference}

Akhtaruzzaman, M., Boubaker, S., Sensoy, A., 2021. Financial contagion during COVID-19 crisis. Financ. Res. Lett. https://doi.org/10.1016/j.frl.2020.101604

Akinsomi, O., 2020. How resilient are REITs to a pandemic? The COVID-19 effect. J. Prop. Invest. Financ. https://doi.org/10.1108/JPIF-06-2020-0065

Alemzero, D.A., Iqbal, N., Iqbal, S., Mohsin, M., Chukwuma, N.J., Shah, B.A., 2020a. Assessing the perceived impact of exploration and production of hydrocarbons on households perspective of environmental regulation in Ghana. Environ. Sci. Pollut. Res. https://doi.org/10.1007/s11356-02010880-3

Alemzero, D.A., Sun, H., Mohsin, M., Iqbal, N., Nadeem, M., 2020b. Assessing energy security in Africa based on multi-dimensional approach of principal composite analysis.

Anser, M.K., Abbas, Q., Chaudhry, I.S., Khan, A., 2020a. Optimal oil stockpiling, peak oil, and general equilibrium: case study of South Asia (oil importers) and Middle East (oil supplier). Environ. Sci. Pollut. Res. https://doi.org/10.1007/s11356-020-08419-7

Anser, M.K., Ali, M., Anwar, F., Usman, M., 2020b. Subjective Age and Job Satisfaction: A Moderated Mediation Model of Job Burnout and Chronological Age. Front. Public Heal. https://doi.org/10.3389/fpubh.2020.00062 
Anser, M.K., Yousaf, Z., Awan, U., Nassani, A.A., Abro, M.M.Q., Zaman, K., 2020c. Identifying the carbon emissions damage to international tourism: Turn a blind eye. Sustain. https://doi.org/10.3390/su12051937

Anser, M.K., Yousaf, Z., Majid, A., Yasir, M., 2020d. Does corporate social responsibility commitment and participation predict environmental and social performance? Corp. Soc. Responsib. Environ. Manag. https://doi.org/10.1002/csr.1977

Anser, M.K., Yousaf, Z., Usman, M., Yousaf, S., Fatima, N., Hussain, H., Waheed, J., 2020e. Strategic business performance through network capability and structural flexibility. Manag. Decis. https://doi.org/10.1108/MD-06-2019-0741

Ashraf, B.N., 2020a. Economic impact of government interventions during the COVID-19 pandemic: International evidence from financial markets. J. Behav. Exp. Financ. https://doi.org/10.1016/j.jbef.2020.100371

Ashraf, B.N., 2020b. Stock markets' reaction to COVID-19: Cases or fatalities? Res. Int. Bus. Financ. https://doi.org/10.1016/j.ribaf.2020.101249

Asif, M., Khan, K.B., Anser, M.K., Nassani, A.A., Abro, M.M.Q., Zaman, K., 2020. Dynamic interaction between financial development and natural resources: Evaluating the 'Resource curse' hypothesis. Resour. Policy. https://doi.org/10.1016/j.resourpol.2019.101566

Aydın, L., Ari, I., 2020. The impact of Covid-19 on Turkey's non-recoverable economic sectors compensating with falling crude oil prices: A computable general equilibrium analysis. Energy Explor. Exploit. https://doi.org/10.1177/0144598720934007

Barbier, E.B., Burgess, J.C., 2020. Sustainability and development after COVID-19. World Dev. https://doi.org/10.1016/j.worlddev.2020.105082

Breitung, J., Candelon, B., 2006. Testing for short- and long-run causality: A frequency-domain approach. J. Econom. 132, 363-378. https://doi.org/10.1016/j.jeconom.2005.02.004

Chandio, A.A., Jiang, Y., Rehman, A., Twumasi, M.A., Pathan, A.G., Mohsin, M., 2020. Determinants of demand for credit by smallholder farmers': a farm level analysis based on survey in Sindh, Pakistan. J. Asian Bus. Econ. Stud. ahead-of-p. https://doi.org/10.1108/jabes-01-2020-0004

Corbet, S., Larkin, C., Lucey, B., 2020. The contagion effects of the COVID-19 pandemic: Evidence from gold and cryptocurrencies. Financ. Res. Lett. https://doi.org/10.1016/j.frl.2020.101554

Daughton, C.G., 2020. Wastewater surveillance for population-wide Covid-19: The present and future. Sci. Total Environ. https://doi.org/10.1016/j.scitotenv.2020.139631

Engelhardt, N., Krause, M., Neukirchen, D., Posch, P.N., 2021. Trust and stock market volatility during the COVID-19 crisis. Financ. Res. Lett. https://doi.org/10.1016/j.frl.2020.101873

Feng, Q., Sun, X., Liu, C., Li, J., 2020. Spillovers between sovereign CDS and exchange rate markets: the role of market fear. North Am. J. Econ. Financ. https://doi.org/10.1016/j.najef.2020.101308

Geweke, J., 1992. Evaluating the Accuracy of Sampling-Based Approaches to the Calculation of Posterior Moments. Bayesian Stat. 4.

Haroon, O., Rizvi, S.A.R., 2020. COVID-19: Media coverage and financial markets behavior-A sectoral inquiry. J. Behav. Exp. Financ. https://doi.org/10.1016/j.jbef.2020.100343 
He, Q., Liu, J., Wang, S., Yu, J., 2020. The impact of COVID-19 on stock markets. Econ. Polit. Stud. https://doi.org/10.1080/20954816.2020.1757570

Huynh, T.L.D., Nasir, M.A., Vo, X.V., Nguyen, T.T., 2020. "Small things matter most": The spillover effects in the cryptocurrency market and gold as a silver bullet. North Am. J. Econ. Financ. https://doi.org/10.1016/j.najef.2020.101277

Ikram, M., Mahmoudi, A., Shah, S.Z.A., Mohsin, M., 2019. Forecasting number of ISO 14001 certifications of selected countries: application of even GM $(1,1)$, DGM, and NDGM models. Environ. Sci. Pollut. Res. https://doi.org/10.1007/s11356-019-04534-2

Iqbal, N., Fareed, Z., Shahzad, F., He, X., Shahzad, U., Lina, M., 2020. The nexus between COVID-19, temperature and exchange rate in Wuhan city: New findings from partial and multiple wavelet coherence. Sci. Total Environ. 729, 138916. https://doi.org/10.1016/j.scitotenv.2020.138916

Iqbal, W., Fatima, A., Yumei, H., Abbas, Q., Iram, R., 2020. Oil supply risk and affecting parameters associated with oil supplementation and disruption. J. Clean. Prod. 255. https://doi.org/10.1016/j.jclepro.2020.120187

Iqbal, W., Yumei, H., Abbas, Q., Hafeez, M., Mohsin, M., Fatima, A., Jamali, M.A., Jamali, M., Siyal, A., Sohail, N., 2019a. Assessment of wind energy potential for the production of renewable hydrogen in Sindh Province of Pakistan. Processes 7, 196. https://doi.org/10.3390/pr7040196

Iqbal, W., Yumei, H., Abbas, Q., Hafeez, M., Mohsin, M., Fatima, A., Jamali, M.A., Jamali, M., Siyal, A., Sohail, N., 2019b. Assessment of wind energy potential for the production of renewable hydrogen in Sindh Province of Pakistan. Processes 7. https://doi.org/10.3390/pr7040196

Iram, R., Anser, M.K., Awan, R.U., Ali, A., Abbas, Q., Chaudhry, I.S., 2020. Prioritization of Renewable Solar Energy to Prevent Energy Insecurity: An Integrated Role. Singapore Econ. Rev. https://doi.org/10.1142/S021759082043002X

Lopez-Tiro, F., Peregrina-Barreto, H., Rangel-Magdaleno, J., Ramirez-San-Juan, J.C., Ramirez-Cortes, J.M., 2020. Effect of the exposure time in laser speckle imaging for improving blood vessels localization: A wavelet approach, in: I2MTC 2020 - International Instrumentation and Measurement Technology Conference, Proceedings. https://doi.org/10.1109/I2MTC43012.2020.9129242

Lyócsa, Š., Molnár, P., 2020. Stock market oscillations during the corona crash: The role of fear and uncertainty. Financ. Res. Lett. https://doi.org/10.1016/j.frl.2020.101707

Mirza, N., Naqvi, B., Rahat, B., Rizvi, S.K.A., 2020a. Price reaction, volatility timing and funds' performance during Covid-19. Financ. Res. Lett. https://doi.org/10.1016/j.frl.2020.101657

Mirza, N., Rahat, B., Naqvi, B., Rizvi, S.K.A., 2020b. Impact of Covid-19 on corporate solvency and possible policy responses in the EU. Q. Rev. Econ. Financ. https://doi.org/10.1016/j.qref.2020.09.002

Mohsin, M., Hanif, I., Taghizadeh-Hesary, F., Abbas, Q., Iqbal, W., 2021. Nexus between energy efficiency and electricity reforms: A DEA-Based way forward for clean power development. Energy Policy. https://doi.org/10.1016/j.enpol.2020.112052

Mohsin, M., Zhou, P., Iqbal, N., Shah, S.A.A., 2018. Assessing oil supply security of South Asia. Energy 155, 438-447. https://doi.org/10.1016/J.ENERGY.2018.04.116

Narayan, P.K., Phan, D.H.B., Liu, G., 2020. COVID-19 lockdowns, stimulus packages, travel bans, and 
stock returns. Financ. Res. Lett. https://doi.org/10.1016/j.frl.2020.101732

Okorie, D.I., Lin, B., 2020. Stock markets and the COVID-19 fractal contagion effects. Financ. Res. Lett. https://doi.org/10.1016/j.frl.2020.101640

Phan, D.H.B., Narayan, P.K., 2020. Country Responses and the Reaction of the Stock Market to COVID19-a Preliminary Exposition. Emerg. Mark. Financ. Trade. https://doi.org/10.1080/1540496X.2020.1784719

Quigley, M.C., Attanayake, J., King, A., Prideaux, F., 2020. A multi-hazards earth science perspective on the COVID-19 pandemic: the potential for concurrent and cascading crises. Environ. Syst. Decis. https://doi.org/10.1007/s10669-020-09772-1

Rizvi, S.K.A., Mirza, N., Naqvi, B., Rahat, B., 2020. Covid-19 and asset management in EU: a preliminary assessment of performance and investment styles. J. Asset Manag. https://doi.org/10.1057/s41260-020-00172-3

Rowan, N.J., Galanakis, C.M., 2020. Unlocking challenges and opportunities presented by COVID-19 pandemic for cross-cutting disruption in agri-food and green deal innovations: Quo Vadis? Sci. Total Environ. https://doi.org/10.1016/j.scitotenv.2020.141362

Salisu, A.A., Akanni, L.O., 2020. Constructing a Global Fear Index for the COVID-19 Pandemic. Emerg. Mark. Financ. Trade. https://doi.org/10.1080/1540496X.2020.1785424

Sarker, S.A., Wang, S., Mehedi Adnan, K.M., Anser, M.K., Ayoub, Z., Ho, T.H., Tama, R.A.Z., Trunina, A., Hoque, M.M., 2020. Economic viability and socio-environmental impacts of solar home systems for off-grid rural electrification in Bangladesh. Energies. https://doi.org/10.3390/en13030679

Shah, S.A.A., Zhou, P., Walasai, G.D., Mohsin, M., 2019. Energy security and environmental sustainability index of South Asian countries: A composite index approach. Ecol. Indic. 106. https://doi.org/10.1016/j.ecolind.2019.105507

Straif-Bourgeois, S., Robinson, W., 2020. About coronavirus disease 2019 (CoviD-19). J. Health Care Finance.

Sun, H., Pofoura, A.K., Adjei Mensah, I., Li, L., Mohsin, M., 2020. The role of environmental entrepreneurship for sustainable development: Evidence from 35 countries in Sub-Saharan Africa. Sci. Total Environ. 741, 140132. https://doi.org/10.1016/j.scitotenv.2020.140132

Sun, L., Cao, X., Alharthi, M., Zhang, J., Taghizadeh-Hesary, F., Mohsin, M., 2020a. Carbon emission transfer strategies in supply chain with lag time of emission reduction technologies and low-carbon preference of consumers. J. Clean. Prod. 264. https://doi.org/10.1016/j.jclepro.2020.121664

Sun, L., Qin, L., Taghizadeh-Hesary, F., Zhang, J., Mohsin, M., Chaudhry, I.S., 2020b. Analyzing carbon emission transfer network structure among provinces in China: new evidence from social network analysis. Environ. Sci. Pollut. Res. 27, 23281-23300. https://doi.org/10.1007/s11356-020-08911-0

Tehreem, H.S., Anser, M.K., Nassani, A.A., Abro, M.M.Q., Zaman, K., 2020. Impact of average temperature, energy demand, sectoral value added, and population growth on water resource quality and mortality rate: it is time to stop waiting around. Environ. Sci. Pollut. Res. https://doi.org/10.1007/s11356-020-09822-w

The Economy in the Time of Covid-19, 2020. , The Economy in the Time of Covid-19. https://doi.org/10.1596/978-1-4648-1570-6 
Topcu, M., Gulal, O.S., 2020. The impact of COVID-19 on emerging stock markets. Financ. Res. Lett. https://doi.org/10.1016/j.frl.2020.101691

Uddin, M., Chowdhury, A., Anderson, K., Chaudhuri, K., 2021. The effect of COVID - 19 pandemic on global stock market volatility: Can economic strength help to manage the uncertainty? J. Bus. Res. https://doi.org/10.1016/j.jbusres.2021.01.061

Wasif Rasheed, H.M., Anser, M.K., 2017. Effect on Brand Loyalty in Mobile Phone Purchasing (A Case Study In Bahawalpur, Pakistan). J. Public Adm. Gov. https://doi.org/10.5296/jpag.v7i1.11042

Xu, Y., Chen, Z., Peng, M.Y.P., Anser, M.K., 2020. Enhancing Consumer Online Purchase Intention Through Gamification in China: Perspective of Cognitive Evaluation Theory. Front. Psychol. https://doi.org/10.3389/fpsyg.2020.581200

Yarovaya, L., Mirza, N., Abaidi, J., Hasnaoui, A., 2021. Human Capital efficiency and equity funds' performance during the COVID-19 pandemic. Int. Rev. Econ. Financ. https://doi.org/10.1016/j.iref.2020.09.017

Yoshino, N., Taghizadeh-Hesary, F., Otsuka, M., 2020. Covid-19 and Optimal Portfolio Selection for Investment in Sustainable Development Goals. Financ. Res. Lett. https://doi.org/10.1016/j.frl.2020.101695

Yousaf, S., Anser, M.K., Tariq, M., Sahibzada Jawad, S.U.R., Naushad, S., Yousaf, Z., 2020. Does technology orientation predict firm performance through firm innovativeness? World J. Entrep. Manag. Sustain. Dev. https://doi.org/10.1108/WJEMSD-11-2019-0091

Zaremba, A., Kizys, R., Aharon, D.Y., Demir, E., 2020. Infected Markets: Novel Coronavirus, Government Interventions, and Stock Return Volatility around the Globe. Financ. Res. Lett. https://doi.org/10.1016/j.frl.2020.101597

Zhang, D., Hu, M., Ji, Q., 2020. Financial markets under the global pandemic of COVID-19. Financ. Res. Lett. https://doi.org/10.1016/j.frl.2020.101528

Zhang, W., Wang, Y., Yang, L., Wang, C., 2020. Suspending Classes Without Stopping Learning: China's Education Emergency Management Policy in the COVID-19 Outbreak. J. Risk Financ. Manag. https://doi.org/10.3390/jrfm13030055 
Figures

\section{Wavelet Coherence: Stock-covid}

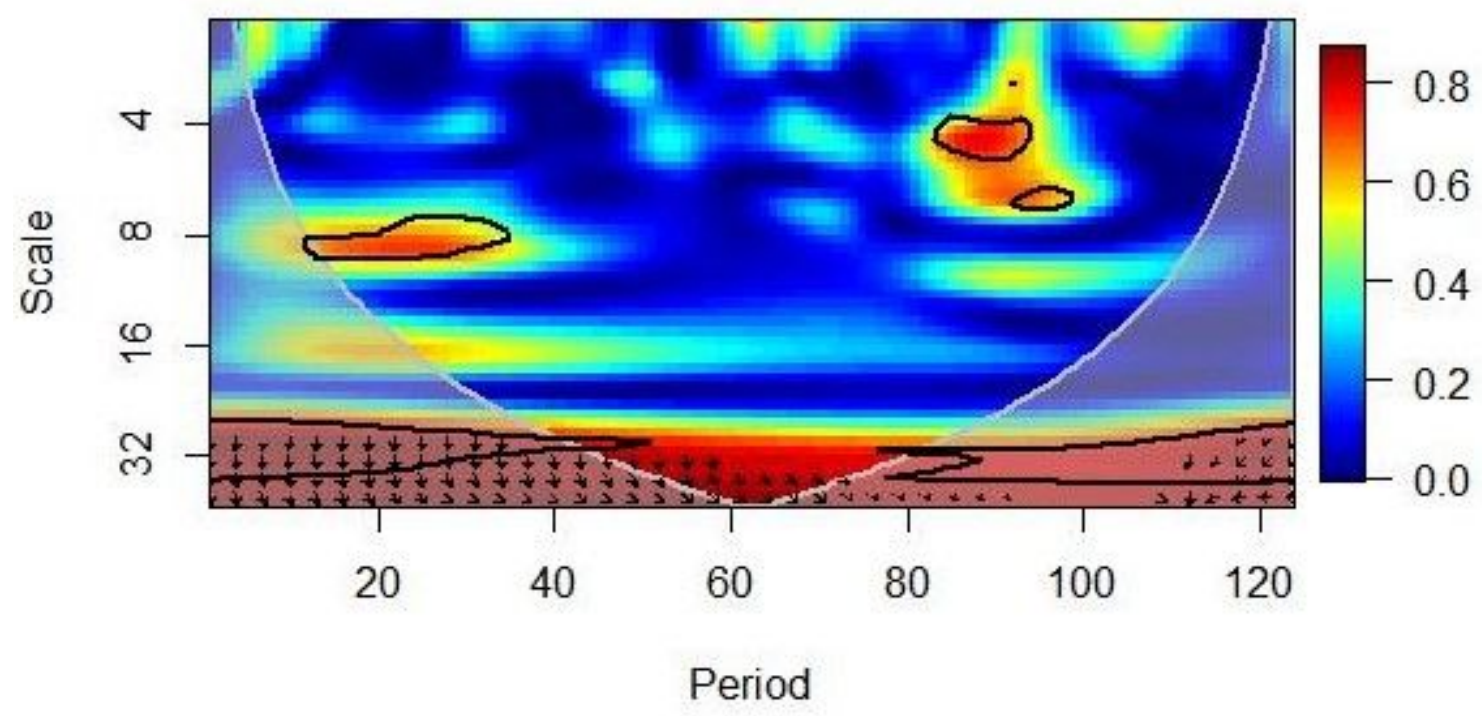

Figure 1

Wavelet coherence between stock return and COVID-19 cases 